\title{
The Potential Molecular Therapeutic Approach in Targeting Ovarian Clear Cell Carcinoma
}

\section{David W Chan and Hextan YS Ngan*}

Department of Obstetrics and Gynaecology, LKS Faculty of Medicine, The University of Hong Kong, Hong Kong SAR, P.R.China

\begin{abstract}
Ovarian Clear Cell Carcinoma (OCCC) is a distinctive subtype of Epithelial Ovarian Cancer (EOC). Compared with other subtypes of EOC, CCC has relatively poor in prognosis and bad outcome in current clinical management using maximal cytoreduction and platinum plus paclitaxel-based combined chemotherapy. Therefore, the investigation of molecular therapeutic approaches targeting at signaling pathways associated with chemoresistance is needed. This review describes some recent potential signaling pathway targets and also suggests putative small molecule kinase inhibitors as well as natural anti-cancer agents in combating this disease.
\end{abstract}

\section{Keywords: GRB7; ERK; FOXM1; Ovarian cancer; High-grade tumor}

Ovarian cancer is the most lethal disease among all gynaecological malignancies. It can be categorized into three major groups according to the origins of the ovarian tumors: (1) epithelial tumors, (2) stromal tumors and (3) germ cell tumors. Among these three groups, Epithelial Ovarian Cancer (EOC) accounts for approximately 90\% of ovarian malignancies and can be divided into four major histological subtypes based on morphological and appearance criteria: serous, mucinous, endometrioid and clear cell carcinoma. Each of these histologic subtypes is further subdivided into benign, borderline and malignant according to their malignant potential [1-3].

Ovarian Clear Cell Carcinoma (OCCC) is distinct histopathologically and clinically from the other EOC subtypes. This tumor has a high incidence at stage I and usually present as a large pelvic mass, rarely exist bilaterally, associated with endometriosis, hypercalcemia as well as thromboembolic vascular complications $[4,5]$. While the incidence of OCCC is not high and accounts 3.7$12.1 \%$ of all EOC $[4,6,7]$, patients with OCCC have a poorer prognosis and higher recurrences than patients with other EOC subtypes [8]. The recent clinical management of advanced EOC includes maximal cytoreduction and platinum plus paclitaxel-based combined chemotherapy. However, the survival rates of OCCC patients are much lower than other advanced EOC such as endometrial subtype $[9,10]$. The poor response of OCCC to platinum-based regimens may be due to the intrinsic chemo-resistance. Therefore, novel treatment approaches such as molecular-targeted therapies plus more effective combinations of new chemotherapeutic agents should be investigated in a prospective clinical trial in OCCC.

Although the underlying mechanisms of chemo-resistance in OCCC remain unclear, a growing body of reports has indicated that several signaling cascades aberrantly activated by genetic alteration are associated with poor response to platinum-based regimens in human cancers [11-16]. Among these signaling pathways, PI3K/AKT/mTOR is the most well-known signaling cascade involved in cisplatin/paclitaxel chemo-resistance of EOC [15-20]. Our laboratory has previously found that loss of MKP3 led to aberrant activation of AKT/ERK1/2 activity [14], whereas overexpression of GRB7/GRB7v was remarkably associated with high-grade ovarian cancer including OCCC and increased AKT/ERK1/2 [21] signaling pathway. Moreover, activated AKT/ERK1/2 could upregulate the expression of crucial oncoprotein FOXM1 which was again significantly associated with high-grade tumors including OCCC [22]. Recent findings also indicated that the overexpressed Serine/Threonine Kinase PAK4 was also associated with OCCC and involved in a variety of tumorigenicity through activating c-Src and MEK1/ERK1/2 [23]. Furthermore, numerous studies have documented that mTOR, an essential modulator in cell proliferation, is frequently upregulated in human cancers including OCCC [24-29]. Therefore, this provides us an attractive target by exploring inhibitors in order to suppress its activity resulting in the elimination of cancer cells. Taken together, these reports have suggested that targeting $\mathrm{PI} 3 \mathrm{~K} / \mathrm{AKT} / \mathrm{ERK} / \mathrm{mTOR}$ signaling cascade may be an effective novel therapeutic approach in OCCC.

Different from conventional anti-cancer drugs, the new trend of target-based therapeutics is the application of small molecule kinase inhibitors in inhibition of cancer cell growth and survival through deregulating of the aberrant activation of signaling activities. To date, more than 10 small molecule kinase inhibitors have been approved by US Food and Drug Administration (FDA) for clinical trial [30,31]. For examples, Raf265 (Novartis), PLX4032 (Roche), AZD6244 (AstraZaneca), ARRY797 (Array BioPaherma) and Sorafenib (Bayer/ Onyx) etc. targeting Raf/MEK/ERK signaling cascade have been tested in different phases of clinical trials in a decade ago [32,33]. Recently, Temsirolimus (Torise $\mathrm{l}^{\mathbb{}}$ ) (Wyeth) and Everolimus (Afinitor ${ }^{\mathbb{}}$ ) (Novartis) (Merck) have been approved to treat patients with advanced and aggressive tumors through inhibiting mTOR mediated cell growth [34-36]. Moreover, Avastin ${ }^{\circledR}$ (bevacizumab), Tarceva (erlotinib) and MK-2206 are approved by FDA in clinical trial for advanced ovarian cancer with failing standard chempotherapy [36-38]. However, the concerning issues include the toxicity or side effects versus potency, as well as the specific inhibition versus multiple targeting when using these small molecule kinase inhibitors.

Another approach is using the combination of current chemotherapeutic reagents and other anti-neoplastic agents which are specifically targeting P13K/AKT/ERK/mTOR signaling axis. For examples, Mabuchi et al. [25] have recently reported that the anticancer substance, Trabectedin or ET743 extracted from the sea squirt Ecteinascidia turbinate, exhibits high efficiency in the treatment of OCCC when in combination with Everolimus [39-41]. The combined

*Corresponding author: Hextan YS Ngan, Department of Obstetrics and Gynaecology, 6/F Professorial Block, Queen Mary Hospital, Pokfulam, Hong Kong, Tel: (852) 2255-4260; Fax: (852) 2255-0947; E-mail: hysngan@hku.hk

Received March 29, 2012; Accepted March 29, 2012; Published April 05, 2012

Citation: Chan DW, Ngan HYS (2012) The Potential Molecular Therapeutic Approach in Targeting Ovarian Clear Cell Carcinoma. Gynecol Obstetric 2:e103. doi:10.4172/2161-0932.1000e103

Copyright: @ 2012 Chan DW, et al. This is an open-access article distributed under the terms of the Creative Commons Attribution License, which permits unrestricted use, distribution, and reproduction in any medium, provided the original author and source are credited. 
application of these drugs was able to sensitize OCCC cells to cisplatinor paclitaxel-induced cell apoptosis in vitro and in vivo through inhibition of AKT/mTOR activity [39]. Apart from Trabectedin, an oral antidiabetic drug Metformin has recently been shown to have potent anti-cancer effects against a variety of human cancers [42-44]. Metformin is the biguanide derivative which has been generally used as the first-line drug for Type 2 diabetes $[45,46]$. But recent evidences from clinical and preclinical studies have shown that Metformin has anti-cancer functions. Clinically, retrospective data have found that diabetic patients with breast cancer receiving Metformin have better response under neoadjuvant chemotherapy [47]. This function is particularly obvious in Her2+ breast cancer patients [48]. Moreover, the combinational use of Metformin and temozolomide (TMZ) is useful to treat Glioblastoma multiforme (GBM) [49]. Mechanistically, the inhibition of cancer cell growth by Metformin is associated with indirect and direct effects. The indirect effect exerted by metformin is linked to the inhibition of treanscriptional activities of key gluconeogenesis genes which in turn elevating insulin sensitivity and decreasing blood glucose and insulin levels [50,51]. The direct effects of Metformin are through activation of AMP-activated protein kinase (AMPK) and inhibition of mammalian target of rapamycin (mTOR) which is an effector governing protein synthesis and gluconeogenesis $[52,53]$. The overall reduction of protein synthesis through inhibition of mTOR is the main mechanism of Metformin action in the inhibition of cancer cell growth. However, most cancer cells have constitutive action of phosphoinositide 3 kinase (PI3K) activity which leads to increased cell survival under chemotherapy treatment. Therefore, the co-treatment of PI3K inhibitor (LY294002) with Metformin can synergistically enhance cisplatin-induced cell apoptosis in ovarian cancer cells [54]. Together, these reports suggest that the use of natural anti-cancer agents is the alternative therapeutic approach in supplement to the current chemotherapeutic regimens against OCCC.

In summary, although current treatment on OCCC always comes across of obstacles in clinical outcome, the exploration of molecular therapeutic approach using small molecular kinase inhibitors or even the intervention of natural anti-cancer agents will provide a new avenue in improving the efficiency of chemotherapy in this disease.

\section{References}

1. Auersperg N, Wong AS, Choi KC, Kang SK, Leung PC (2001) Ovarian surface epithelium: biology, endocrinology, and pathology. Endocr Rev 22: 255-288.

2. Colombo N, Van Gorp T, Parma G, Amant F, Gatta G, et al. (2006) Ovarian cancer. Crit Rev Oncol Hematol 60: 159-179.

3. Lukanova A, Kaaks R (2005) Endogenous hormones and ovarian cancer: epidemiology and current hypotheses. Cancer Epidemiol Biomarkers Prev 14: 98-107.

4. Kennedy AW, Biscotti CV, Hart WR, Webster KD (1989) Ovarian clear cell adenocarcinoma. Gynecol Oncol 32: 342-349.

5. Jenison EL, Montag AG, Griffiths CT, Welch WR, Lavin PT, et al. (1989) Clear cell adenocarcinoma of the ovary: a clinical analysis and comparison with serous carcinoma. Gynecol Oncol 32: 65-71.

6. Omura GA, Brady MF, Homesley HD, Yordan E, Major FJ, et al. (1991) Longterm follow-up and prognostic factor analysis in advanced ovarian carcinoma: the Gynecologic Oncology Group experience. J Clin Oncol 9: 1138-1150.

7. O'Brien ME, Schofield JB, Tan S, Fryatt I, Fisher C, et al. (1993) Clear cell epithelial ovarian cancer (mesonephroid): bad prognosis only in early stages. Gynecol Oncol 49: 250-254

8. Sugiyama T, Kamura T, Kigawa J, Terakawa N, Kikuchi Y, et al. (2000) Clinical characteristics of clear cell carcinoma of the ovary: a distinct histologic type with poor prognosis and resistance to platinum-based chemotherapy. Cancer 88: 2584-2589

9. Gorai I, Nakazawa T, Miyagi E, Hirahara F, Nagashima Y, et al. (1995)
Establishment and characterization of two human ovarian clear cell adenocarcinoma lines from metastatic lesions with different properties. Gynecol Oncol 57: 33-46.

10. Ho CM, Huang YJ, Chen TC, Huang SH, Liu FS, et al. (2004) Pure-type clear cell carcinoma of the ovary as a distinct histological type and improved survival in patients treated with paclitaxel-platinum-based chemotherapy in pure-type advanced disease. Gynecol Oncol 94: 197-203.

11. Park JT, Chen X, Tropè CG, Davidson B, Shih leM, et al. (2010) Notch3 overexpression is related to the recurrence of ovarian cancer and confers resistance to carboplatin. Am J Pathol 177: 1087-1094.

12. Szajnik M, Szczepanski MJ, Czystowska M, Elishaev E, Mandapathil M, et al (2009) TLR4 signaling induced by lipopolysaccharide or paclitaxel regulates tumor survival and chemoresistance in ovarian cancer. Oncogene 28: 43534363

13. Servidei T, Riccardi A, Mozzetti S, Ferlini C, Riccardi R (2008) Chemoresistant tumor cell lines display altered epidermal growth factor receptor and HER3 signaling and enhanced sensitivity to gefitinib. Int J Cancer 123: 2939-2949.

14. Chan DW, Liu VW, Tsao GS, Yao KM, Furukawa T, et al. (2008) Loss of MKP3 mediated by oxidative stress enhances tumorigenicity and chemoresistance of ovarian cancer cells. Carcinogenesis 29: 1742-1750.

15. Xing H, Weng D, Chen G, Tao W, Zhu T, et al. (2008) Activation of fibronectin $\mathrm{PI}-3 \mathrm{~K} / \mathrm{Akt} 2$ leads to chemoresistance to docetaxel by regulating survivin protein expression in ovarian and breast cancer cells. Cancer Lett 261: 108-119.

16. Kim SH, Juhnn YS, Song YS (2007) Akt involvement in paclitaxe chemoresistance of human ovarian cancer cells. Ann N Y Acad Sci 1095: 8289.

17. Rosanò L, Cianfrocca R, Spinella F, Di Castro V, Nicotra MR, et al. (2011) Acquisition of chemoresistance and EMT phenotype is linked with activation of the endothelin A receptor pathway in ovarian carcinoma cells. Clin Cancer Res 17: 2350-2360.

18. Abedini MR, Muller EJ, Bergeron R, Gray DA, Tsang BK (2010) Akt promotes chemoresistance in human ovarian cancer cells by modulating cisplatininduced, p53-dependent ubiquitination of FLICE-like inhibitory protein. Oncogene 29: 11-25.

19. Fraser M, Bai T, Tsang BK (2008) Akt promotes cisplatin resistance in human ovarian cancer cells through inhibition of p53 phosphorylation and nuclear function. Int J Cancer 122: 534-546.

20. Yang X, Fraser M, Moll UM, Basak A, Tsang BK (2006) Akt-mediated cisplatin resistance in ovarian cancer: modulation of p53 action on caspase-dependent mitochondrial death pathway. Cancer Res 66: 3126-3136.

21. Wang Y, Chan DW, Liu VW, Chiu P, Ngan HY (2010) Differential functions of growth factor receptor-bound protein 7 (GRB7) and its variant GRB7v in ovarian carcinogenesis. Clin Cancer Res 16: 2529-2539.

22. Lok GT, Chan DW, Liu VW, Hui WW, Leung TH, et al. (2011) Aberrant activation of ERK/FOXM1 signaling cascade triggers the cell migration/invasion in ovarian cancer cells. PLoS One 6: e23790.

23. Siu MK, Chan HY, Kong DS, Wong ES, Wong OG, et al. (2010) p21-activated kinase 4 regulates ovarian cancer cell proliferation, migration, and invasion and contributes to poor prognosis in patients. Proc Natl Acad Sci U S A 107: 18622 18627.

24. Dazert E, Hall MN (2011) mTOR signaling in disease. Curr Opin Cell Biol 23 744-755.

25. Mabuchi S, Hisamatsu T, Kimura T (2011) Targeting mTOR signaling pathway in ovarian cancer. Curr Med Chem 18: 2960-2968.

26. Souza EC, Ferreira AC, Carvalho DP (2011) The mTOR protein as a target in thyroid cancer. Expert Opin Ther Targets 15: 1099-1112.

27. Voss MH, Molina AM, Motzer RJ (2012) mTOR inhibitors in advanced renal cel carcinoma. Hematol Oncol Clin North Am 25: 835-852.

28. Al-Batran SE, Ducreux M, Ohtsu A (2010) mTOR as a therapeutic target in patients with gastric cancer. Int J Cancer 130: 491-496.

29. Kudo M (2011) mTOR inhibitor for the treatment of hepatocellular carcinoma Dig Dis 29: 310-315.

30. Zhang J, Yang PL, Gray NS (2009) Targeting cancer with small molecule kinase inhibitors. Nat Rev Cancer 9: 28-39. 
31. Wu P, Hu YZ (2010) PI3K/Akt/mTOR pathway inhibitors in cancer: a perspective on clinical progress. Curr Med Chem 17: 4326-4341.

32. Bartholomeusz C, Oishi T, Saso H, Akar U, Liu P, et al. (2012) MEK1/2 Inhibitor Selumetinib (AZD6244) Inhibits Growth of Ovarian Clear Cell Carcinoma in a PEA-15-Dependent Manner in a Mouse Xenograft Model. Mol Cancer Ther 11: $360-369$.

33. Roberts PJ, Der CJ (2007) Targeting the Raf-MEK-ERK mitogen-activated protein kinase cascade for the treatment of cancer. Oncogene 26: 3291-3310.

34. Behbakht K, Sill MW, Darcy KM, Rubin SC, Mannel RS, et al. (2011) Phase II trial of the mTOR inhibitor, temsirolimus and evaluation of circulating tumo cells and tumor biomarkers in persistent and recurrent epithelial ovarian and primary peritoneal malignancies: a Gynecologic Oncology Group study. Gynecol Oncol 123: 19-26.

35. Coppin C (2010) Everolimus: the first approved product for patients with advanced renal cell cancer after sunitinib and/or sorafenib. Biologics 4: 91-101.

36. Hirai H, Sootome H, Nakatsuru Y, Miyama K, Taguchi S, et al. (2010) MK2206, an allosteric Akt inhibitor, enhances antitumor efficacy by standard chemotherapeutic agents or molecular targeted drugs in vitro and in vivo. Mo Cancer Ther 9: 1956-1967.

37. Cheng X, Moroney JW, Levenback CF, Fu S, Jaishuen A, et al. (2009) What is the benefit of bevacizumab combined with chemotherapy in patients with recurrent ovarian, fallopian tube or primary peritoneal malignancies? J Chemother 21: 566-572.

38. Hirte H, Oza A, Swenerton K, Ellard SL, Grimshaw R, et al. (2010) A phase I study of erlotinib (OSI-774) given in combination with carboplatin in patients with recurrent epithelial ovarian cancer (NCIC CTG IND.149). Gynecol Oncol 118: 308-312.

39. Mabuchi S, Hisamatsu T, Kawase C, Hayashi M, Sawada K, et al. (2011) The activity of trabectedin as a single agent or in combination with everolimus for clear cell carcinoma of the ovary. Clin Cancer Res 17: 4462-4473.

40. Bonetta L (2001) Anticancer squirt. Nat Med 7: 891.

41. Nastrucci C, Cesario A, Russo P (2012) Anticancer Drug Discovery from the Marine Environment. Recent Pat Anticancer Drug Discov 7: 218-232.
42. Dowling RO, Niraula S, Stambolic V, Goodwin PJ (2012) Metformin in Cancer: Translational Challenges. J Mol Endocrinol 48: R31-43.

43. Bost F, Sahra IB, Le Marchand-Brustel Y, Tanti JF (2012) Metformin and cancer therapy. Curr Opin Oncol 24: 103-108.

44. Micic D, Cvijovic G, Trajkovic V, Duntas LH, Polovina S (2011) Metformin: its emerging role in oncology. Hormones (Athens) 10: 5-15.

45. Melchior WR, Jaber LA (1996) Metformin: an antihyperglycemic agent for treatment of type II diabetes. Ann Pharmacother 30: 158-164.

46. Holman R (2007) Metformin as first choice in oral diabetes treatment: the UKPDS experience. Journ Annu Diabetol Hotel Dieu 13-20.

47. Jiralerspong S, Palla SL, Giordano SH, Meric-Bernstam F, Liedtke C, et al. (2009) Metformin and pathologic complete responses to neoadjuvant chemotherapy in diabetic patients with breast cancer. J Clin Oncol 27: 3297 3302.

48. He X, Esteva FJ, Ensor J, Hortobagyi GN, Lee MH, et al. (2011) Metformin and thiazolidinediones are associated with improved breast cancer-specific survival of diabetic women with HER2+ breast cancer. Ann Oncol.

49. Soritau O, Tomuleasa C, Aldea M, Petrushev B, Susman S, et al. (2011) Metformin plus temozolomide-based chemotherapy as adjuvant treatment for WHO grade III and IV malignant gliomas. J BUON 16: 282-289.

50. Caton PW, Nayuni NK, Kieswich J, Khan NQ, Yaqoob MM, et al. (2010) Metformin suppresses hepatic gluconeogenesis through induction of SIRT1 and GCN5. J Endocrinol 205: 97-106.

51. Gonzalez-Angulo AM, Meric-Bernstam F (2010) Metformin: a therapeutic opportunity in breast cancer. Clin Cancer Res 16: 1695-1700.

52. Jalving M, Gietema JA, Lefrandt JD, de Jong S, Reyners AK, et al. (2010) Metformin: taking away the candy for cancer? Eur J Cancer 46: 2369-2380.

53. Kim YD, Park KG, Lee YS, Park YY, Kim DK, et al. (2008) Metformin inhibits hepatic gluconeogenesis through AMP-activated protein kinase-dependent regulation of the orphan nuclear receptor SHP. Diabetes 57: 306-314.

54. Li C, Liu VW, Chan DW, Yao KM, Ngan HY (2012) LY294002 and metformin cooperatively enhance the inhibition of growth and the induction of apoptosis of ovarian cancer cells. Int J Gynecol Cancer 22: 15-22.
Submit your next manuscript and get advantages of OMICS Group submissions

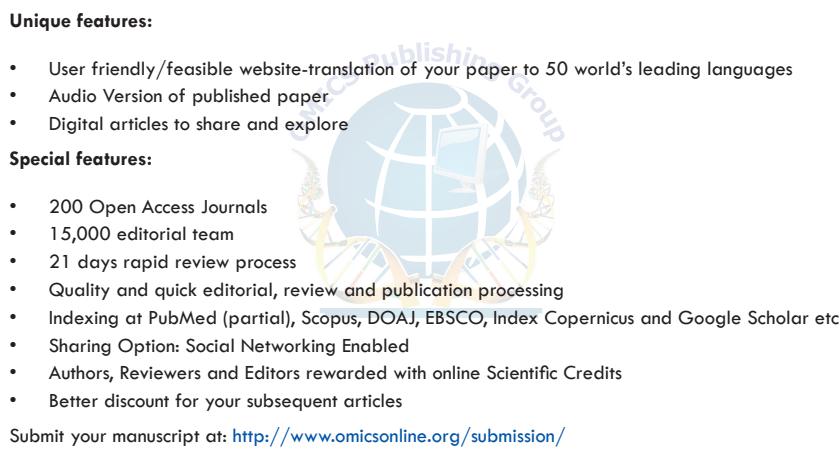

